Available online on 15.09.2017 at http://iddtonline.info
Journal of Drug Delivery and Therapeutics
O 2011-17, publisher and licensee JDDT, This is an Open Access article which permits unrestricted
noncommercial use, provided the original work is properly cited

Open 2 Access

Research Article

\title{
SOLUBILITY AND DISSOLUTION ENHANCEMENT OF WATER INSOLUBLE DRUG BY USING DIFFERENT HYDROPHILLIC CARRIERS AND FORMULATED INTO TABLET DOSAGE FORM
}

\author{
${\text { Prachi Sharma*1, }{ }^{*} \text { aranjit Kaur }}^{2}$, Ajeet Pal Singh ${ }^{3}$ \\ Department of Pharmaceutics, St. Soldier Institute of Pharmacy, Behind NIT, Jalandhar (Punjab), India-144011
}

\begin{abstract}
Rosuvastatin calcium is a BCS class II drug (low solubility and high permeability), used as a lipid lowering agent by acting as HMG CoA reductase inhibitor and it is used for the management of hyperlipidemia. Increase in the solubility of the poorly water soluble drug is the most challenging aspect for various new chemical entities which leads to the unsatisfactory dissolution profile, consequently, the bioavailability. There are various techniques to enhance the solubility of the drug, such as particle size reduction, nanosuspension, use of surfactants, salt formation, $\mathrm{pH}$ modifier, solid dispersion etc. Solid dispersions in water-soluble carriers have attracted considerable interest as a means of improving the dissolution rate and hence possibly bioavailability, of a range of hydrophobic drugs.Carriers are the major players in these formulations, e.g., hydroxypropylmethylcellulose, ethyl cellulose, methyl cellulose, polyvinyl pyrrolidone, polyvinyl alcohol etc. HPMC and EC is one of the most efficient polymers among all of these to work as a carrier for these drugs to enhance solubility. Four ratios of drug: Carriers were prepared $(1: 1,1: 3,1: 5,1: 7)$ and 1:7 was the optimized ratio which shows a maximum release of the drug via dissolution profile. In the present work, Solid Dispersions were prepared by Kneading technique to enhance the solubility of Rosuvastatin Calcium. Solid dispersions were evaluated for Fourier transform infrared spectroscopy (FTIR), thermal analysis, dissolution studies, powder X-ray diffraction (PXRD), scanning electron microscopy (SEM), and stability studies to confirm enhancement in solubility. The prepared solid dispersions are formulated into tablet dosage form and characterized by various parameters i.e. weight variation, hardness, friability, disintegration, and dissolution rate. The evaluated parameters of tablet dosage form show increase in solubility and dissolution rate of the pure drug.
\end{abstract}

Keywords: Rosuvastatin Calcium, Carriers, HPMC, EC, Solid Dispersion Tablet

Article Info: Received 12 July, 2017; Review Completed 03 Sep, 2017; Accepted 04 Sep, 2017; Available online 15 Sep, 2017

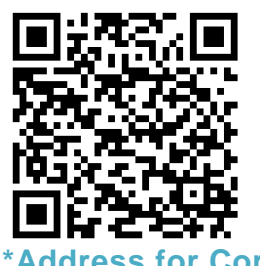

Cite this article as:

Sharma S, Kaur T, Singh AP, Solubility and dissolution enhancement of water insoluble drug by using different hydrophillic carriers and formulated into tablet dosage form, Journal of Drug Delivery and Therapeutics. 2017; $7(5): 86-93$

DOI: http://dx.doi.org/10.22270/jddt.v7i5.1491

*Address for Correspondence

Prachi Sharma, Department of Pharmaceutics, St. Soldier Institute of Pharmacy, Behind NIT, Jalandhar (Punjab), India-144011

\section{INTRODUCTION}

Oral bioavailability of a drug depends on its solubility and dissolution rate, and dissolution rate may be rate determining step for appearance of medicinal effect, therefore need to be increased the dissolution of drug with limited water solubility is often needed. Various methods are used to improve these characteristics, including salt formation, micronization and addition of solvent or surface active agents. Solid dispersion (SD) is one of the suitable method in which the dispersion of one or more active ingredients in an inner carrier or matrix in solid state prepared by melting, dissolution in solvent or melting solvent method. The Important phenomenon in pharmaceutical formulations form is solubility and dissolution which plays a vital and significant role in pharmaceutical dosage form. "Solubility' is defined as maximum amount of solute that can be dissolved in a given amount of solvent" and dissolution is defined as a process in which a solid 
substance solublised in a given solvent i.e. mass transfer from the solid surface to the liquid phase. ${ }^{1,2,3,4}$

Orally administered solid dosage form i.e. tablet or capsule, should be released from the dosage form and dissolved in the gastrointestinal fluids before it can be absorbed and therefore, the oral bioavailability of different poorly water soluble drugs is limited by their dissolution rates which is the amount of solid substance that goes into solution per unit time under standard conditions of temperature, $\mathrm{pH}$ and solvent composition and constant solid surface area, and increase in the dissolution of poorly water soluble drugs by using solid dispersion techniques presented a challenge to the formulation scientists. $\mathbf{5 , 6}$

The concept of solid dispersions was originally proposed by (Sekiguchi and Obi) solid dispersion represents a useful technique for increasing the solubility, dissolution and improves the therapeutic efficacy of drugs. The term solid dispersion refers to a group of solid products consisting of at least two different components, i.e. a hydrophilic matrix and a hydrophobic drug. The most diffrent hydrophilic carriers used for solid dispersions include polyvinylpyrrolidone (Povidone, PVP), polyethylene glycols (PEGs), hydroxyl propyl methyl cellulose, ethyl cellulose and so on. $7,8,9$

Rosuvastatin (RST) is a crystalline, poorly water soluble drug and therapeutically HMG-CA reductase inhibitor. Currently, using as a potent lipid lowering agent and hypolipidemic agent. Clinically, in some cases it is also used in osteoporosis, benign prostatic hyperplasia and Alziemer's Disease. It is having $20 \%$ oral bioavailability and its $t 1 / 2$ will be 19 hours. Therefore, the aim of the present study is to enhance the solubility and dissolution of pure drug by using solid dispersion technique and formulated into tablet dosage form. ${ }^{10,11}$

\section{MATERIALS AND METHODS}

\section{Materials}

Rosuvastatin calcium is lipid lowering agent, drug gifted by (Biocon Pvt Ltd. Banglore, India), HPMC and Ethyl Cellulose used as a polymer by (S.D Fine Chemicals, Mumbai), Ehanol used as a sovent by (Balaji Drugs, Changshiu Yangyuan. China), Methanol is also a solvent by (S.D Fine Chemicals. Mumbai), Lactose is used as a diluents and Talc is used as glidant by(S.D Fine Chemicals.Mumbai) and Magnesium stearate is used as Lubricant supplied by (National Chemicals. Mumbai). All chemicals were of analytical or technical grade and were used without further treatment.

Methodology ${ }^{12,13,14}$

\section{Preformulation studies}

Pre-formulation studies on active pharmaceutical ingredients (API), inactive ingredients (Excipients), and their combinations were carried out to finalize specifications of active pharmaceutical ingredients, to study the chemical compatibility between active and inactive ingredient, FTIR studies for Rosuvastatin, Hpmc and Ethylcellulose were carried out by weighing approximately $1-3 \mathrm{mg}$ of the sample and $0.1 \mathrm{~g}$ of previously dried potassium bromide. Carefully grind the mixture and place the homogeneous mixture in an IR pellet die. The $\mathrm{KBr}$ disks were prepared by compressing the powder. The scanning range was kept from 4000$450 \mathrm{~cm}^{-1}$. The flow properties like bulk density, tapped density, compressibility index and hausners ratio were determined by using tapped density tester and flow characteristics were determined by using angle of repose method to evaluate the flowability of the drug and excipients blend.

\section{Melting Point Determination}

The melting point of the Rosuvastatin Calcium was determined by capillary fusion method. A capillary sealed at one end was filled with small amount of drug and the capillary was kept inverted i.e. sealed end down words into the melting point apparatus.

\section{Determination of Absorption Maxima ( $\lambda$ max)}

The absorption maxima of the drug was determined by scanning $(10 \mu \mathrm{g} / \mathrm{ml})$ solution of drug in methanol between 200-400nm by UV spectroscopy.

\section{Determination of Solubility}

Solubility studies were carried out according to the method reported by Higuchi and Connors. Pure drug sample dissolved in $10 \mathrm{ml}$ of distilled water and was shaken in rotary shaker for 24 hours. After shaking, the solution was filtered and their absorbance by UVspectroscopy

\section{Preparation of Standard Curve in Phosphate Buffer (pH 6.8)}

\section{Preparation of phosphate Buffer (pH 6.8)}

Take 28.80gm of disodium hydrogen phosphate and $11.45 \mathrm{gm}$ of Potassium dihydrogen phosphate in sufficient water to produce $1000 \mathrm{ml}$.

\section{Preparatrion of Standard plot}

$50 \mathrm{mg}$ of drug dissolved in small amount of methanol and dilute to $100 \mathrm{ml}$ with phosphate buffer $\mathrm{pH} 6.8,50 \mathrm{ml}$ of this solution was taken and dilute to $100 \mathrm{ml}$ with phosphate buffer $\mathrm{pH} 6.8$ to prepare stock solution of 250 $\mu \mathrm{g} / \mathrm{ml}$. From this solution take $0.1,0.2,0.3,0.4,0.6$ and $0.8 \mathrm{ml}$ and transferred it into $10 \mathrm{ml}$ volumetric flask and volume make upto $10 \mathrm{ml}$ with phosphate buffer and take absorbance at $241 \mathrm{~nm}$ using phosphate buffer as blank.

\section{Preparation of binary system of solid dispersion by Kneading method}

The pure drug sample and different polymers were weighed accurately in different ratios and kneaded for $30 \mathrm{~min}$ and add the ethanol:water(1:1) solution into the pastle and mortar. The prepared mixture dried in hot air oven and after drying and pulverized the mixture screen from Sieve no.60 and stored in the airtight container for further.

\section{Characterization of Solid Dispersions}

The prepared solid dispersions were evaluated for percent drug content, solubility studies, Fourier transform infrared (FTIR), Differential scanning calorimetry (DSC), SEM (Scanning electron 
microscopy),X-ray diffraction (XRD), in vitro drug release and dissolution efficiency.

\section{Determination of Drug Content}

10mg of drug: polymer was accurately weighed and transferred to $10 \mathrm{ml}$ volumetric flask and volume was made up to the mark with $\mathrm{pH} 6.8$ phosphate buffer and determine the absorbance at $241 \mathrm{~nm}$ by using organic solvent as blank. The drug content of Rosuvastatin was calculated using standard curve.

\section{In vitro Drug Release}

In-vitro dissolution of Rosuvastatin solid dispersions were studied in USP dissolution apparatus (Electro lab) employing a basket stirrer. $900 \mathrm{ml}$ of phosphate buffer of $\mathrm{pH} 6.8$ was used as dissolution medium at $50 \mathrm{rpm}$. The temperature of $37+0.5^{\circ} \mathrm{C}$ was maintained throughout the experiment. Solid dispersions equivalent to $10 \mathrm{mg}$ of RST was used in each test. $5 \mathrm{ml}$ of sample of dissolution medium were withdrawn by means of pipette fitted with pre-filter at known intervals of time and analyzed for drug release by measuring the absorbance at $241 \mathrm{~nm}$ after suitable dilution with phosphate buffer. The volume withdrawn at each time interval was replaced with fresh quantity of dissolution medium. The amount of RST released was calculated and plotted against time and compared with pure drug.

\section{Fourier Transform Infrared (FTIR) Spectroscopy}

Fourier Transform Infrared (FTIR) spectra of pure drug, HPMC and EC, physical mixture and solid dispersion were determined on samples prepared in potassium bromide $(\mathrm{KBr})$ disks. Samples were prepared in $\mathrm{KBr}$ disks by means of a hydrostatic press. The scanning range was 400 to $4000 \mathrm{~cm}^{-1}$ and the resolution was 4 $\mathrm{cm}^{1}$.

\section{Differential Scanning Calorimetry (DSC)}

The samples (5 $\mathrm{mg}$ each) were placed into pierced aluminum container. The studies were performed under static air atmosphere in the temperature range of $20^{\circ} \mathrm{C}$ to $400^{\circ} \mathrm{C}$ at a heating rate of $10^{\circ} \mathrm{C} / \mathrm{min}$.

\section{Powder X-Ray Diffraction (XRD) Analysis}

The X-Ray Diffraction (XRD) study of pure drug, HPMC and EC solid dispersion were recorded using Xray diffractrometer. Target $\mathrm{CuKa}$ monochromatized radiation, voltage $40 \mathrm{KV}$, and current $40 \mathrm{~mA}$ at ambient temperature and data were collected by using scan mode a step size of 0.010 at $20 / \mathrm{s}$.

\section{Formulation of Blends ${ }^{15,16,17}$}

Rosuvastatin calcium: HPMC: EC solid dispersion and excipients i.e., Lactose were co-grounded in pestle mortar (except talc and magnesium stearate) and were passed through mesh. No.60 and finally talc and magnesium stearate were added and mixed for 5 minutes and prepare the powder dosage form.

\section{Bulk Density}

Bulk density is defined as the mass of powder divided by the bulk volume and is expressed as $\mathrm{g} / \mathrm{cm} 3$ and bulk density was calculated using the formula. $\rho_{b=} M / V_{b}$

eq. no(1)

where $\rho_{b}=$ apparent bulk density, $M=$ weight of powder and $\mathrm{V}_{\mathrm{b}}=$ bulk volume

\section{Tapped Density}

It can be defined as mass of blend in the measuring cylinder divided by its tapped volume. The measuring cylinder containing a known mass of blend was tapped 100 times using density apparatus. The tapped density was calculated using the formula.

$$
\boldsymbol{\rho}_{\mathbf{t}=\mathbf{M}} \mathbf{M} \mathbf{V}_{\mathbf{t}} \text { eq. no(2) }
$$

where $\mathrm{V}_{\mathrm{t}}=$ minimum volume and $\mathrm{M}=$ weight of the blend

\section{Compressibility Index}

The simplest way for measurement of flow of powder is its compressibility, an indication of the ease with which a material can be induced to flow is given by compressibility index (I) which is calculated as follows:

$$
\mathbf{I}=\boldsymbol{\rho}_{\mathrm{t}-} \boldsymbol{\rho}_{\mathrm{b} /} \boldsymbol{\rho}_{\mathrm{t} \times} \mathbf{1 0 0} \quad \text { eq. no(3) }
$$

Where, $\rho \mathrm{t}=$ Tapped density, $\rho \mathrm{b}=$ Bulk density

\section{Hausner Ratio}

Hausner ratio (HR) is an indirect index of ease of powder flow. It is calculated by the following formula

$$
\mathbf{H r}=\boldsymbol{\rho}_{\mathrm{t} /} \boldsymbol{\rho}_{\mathrm{b}} \quad \text { eq no.(4) }
$$

Where, $\rho t$ is tapped density and $\rho b$ is bulk density.

Lower Hausner ratio $(<1.25)$ indicates better flow properties than higher ones (>1.25).

\section{Angle of Repose}

Angle of Repose was determined using funnel method. The blend was poured through a funnel that can be raised vertically until a specified cone height (h) was obtained. Radius of the heap ( $r$ ) was measured and angle of repose $(\theta)$ was calculated using the formula.

$\operatorname{Tan} \theta=h / \mathbf{r}$ eq no.(5)

Therefore $\theta_{\Xi} \tan ^{-1}(\mathrm{~h} / \mathrm{r})$ Eq no. (5)

\section{Tablet Preparation method}

\section{Wet granulation method}

It is the most common and widely used method. This method involves various steps like weighing of ingredients, mixing, granulation, screening of damp pass, drying, lubrication and compression of tablets. The main active ingredient, diluents, disintegrants are blended together, then it is allowed to pass through the sieve (sifting). Solutions of the binding agent are added to the initial mixture with stirring. The amount of binding agent added should be sufficient, in order to avoid over wetting of the tablet. If the powder is not wetted properly, the granules will be too soft and can be broken down during lubrication, which is difficult during compression of tablet. After drying the granules, they are allowed to pass through the screen; usually 60100 mesh nylon cloth is used. After dry granulation, lubricant is added as fine powder, which is required for proper filling of the die cavity. 


\section{Evaluation Parameters of Tablet Dosage Form}

\section{General appearance}

It includes overall appearance of the tablet like size, shape, odor, taste, color, surface, consistency, textures physical flaws. Tablet thickness should be controlled with $\pm 5 \%$ variation of standard value.

\section{Weight variation test}

Twenty tablets were weighed accurately and the average weight of the tablet is determined. As per the IP specification, if the tablets weight is:

Table 1: Showing Weight variation test

\begin{tabular}{|l|l|}
\hline Weight ot Tab(mg) & Acceptance criteria \\
\hline$<80$ & $10 \%$ \\
\hline $80-250$ & $7.5 \%$ \\
\hline$>250$ & $5 \%$ \\
\hline
\end{tabular}

If any tablet deviates from the specification, another 10 tablets are selected from the batch and the same procedure is repeated. In case of 30 tablets, not more than one tablet should deviate.

\section{Hardness test}

It is defined as the force required breaking the tablet. Ten tablets from each batch were selected and hardness was measured using Digital hardness tester to find the average tablet hardness or crushing strength. Hardness should be in between $3-6 \mathrm{~kg} / \mathrm{cm} 2$.

\section{Friability test}

The friability values of the tablets were determined using a Roche friabilator. It is expressed in \%. 20 tablets were initially weighed (initial weight) and transferred to friabilator. Friabilator was operated at $25 \mathrm{rpm}$ for $4 \mathrm{~min}$. Percentage friability was calculated using the following equation. Friability of tablets less than $1 \%$ was considered acceptable.

$$
\% \text { Friability }=\frac{\text { Initial weight }- \text { final weight }}{\text { Initial weight }} \times 100
$$

\section{Disintegration test}

It is defined as the breakdown of tablet into finely divided particulates or granules in GI tract. Six tablets were taken randomly from each batch and placed in USP disintegration apparatus baskets, which is repeatedly immersed 30 times per minute into a thermostatically controlled fluid at $37^{\circ} \mathrm{C}$ and observed over the time described in the individual monograph.

\section{In vitro-dissolution studies}

The release rate of Rosuvastatin calcium 1 tablets was determined using USP Dissolution Testing Apparatus II (Paddle type). The dissolution test was performed using $900 \mathrm{ml}$ of Phosphate buffer $\mathrm{pH} 6.8$, at $37 \pm 0.5^{\circ} \mathrm{C}$ and speed of $50 \mathrm{rpm}$. Aliquot $(5 \mathrm{ml})$ of the solution was collected from the dissolution apparatus for every 10min and were replaced with fresh dissolution medium. The aliquots were filtered through whatmann filter paper no.41. Absorbance of these solutions was recorded at $241 \mathrm{~nm}$ (Rosuvastatin calcium) in photometric mode.
Aliquots were withdrawn at ten minute interval from a zone midway between the surface of dissolution medium and the top of rotating paddle not less than 1 $\mathrm{cm}$ apart from the vessel wall.

\section{Stability Studies}

Accelerated stability studies were performed on prepared solid dispersion tablet dosage form in amber colored screw capped bottles and were checked as per ICH guidelines at $40 \%+2{ }^{\circ} \mathrm{Cand} 75 \%+5 \% \mathrm{RH}$ up to one month. The tablets were kept in stability chamber. Sample were removed at regular intervals as initial, 7 days, 14 days, 21 days and 30 days and were analyzed for physical characterization, content uniformity and in vitro dissolution studies. The similarity factor (f2) was used as a basis to compare dissolution profiles. The dissolution profiles are considered to be similar when f2 is between 50 and 100. The dissolution profiles of tablet formulations before and after stability testing were compared using a similarity factor (f2) which is calculated from the following formula:

$$
f_{2}=50 \cdot \log \left\{\left[1+(1 / n) \Sigma_{t=1} n\left(R_{t}-T_{t}\right) 2\right]-0.5 \cdot 100\right\}
$$

\section{RESULTS AND DISCUSSION}

\section{Preformulation Studies:}

\section{1) FTIR of pure drug}

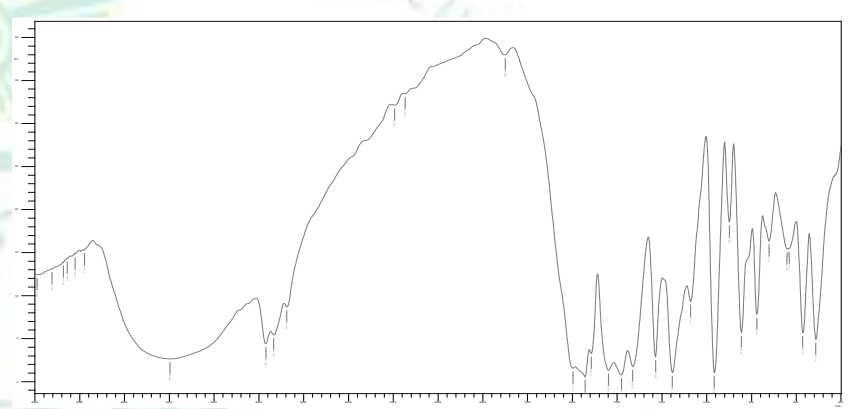

Figure 1: FTIR of Rosuvastatin Calcium

\section{2) Melting point determination by Dsc}

The DSC of the pure drug sample as shown below in figure 2

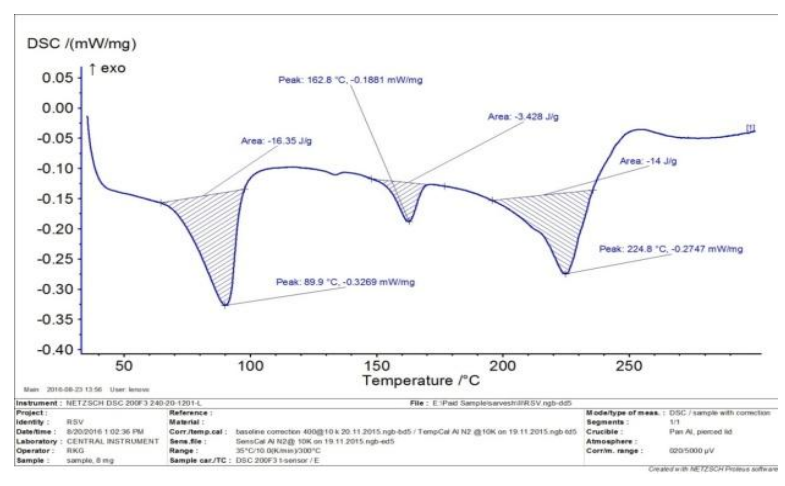

Figure 2: DSC thermogram of Rosuvastatin Calcium

\section{3) Absorption Maxima}

Absorption maxima ( $\lambda \max )$ of Rosuvastatin Calcium were observed in different solvents 
Table 2: Absorption maxima ( $\lambda \max$ ) of the Rosuvastatin Calcium in different solvent

\begin{tabular}{|l|l|}
\hline Solvent & $(\lambda \mathbf{m a x}) \mathbf{n m}$ \\
\hline Phosphate buffer & $241 \mathrm{~nm}$ \\
\hline Water & $240 \mathrm{~nm}$ \\
\hline Methanol & $239 \mathrm{~nm}$ \\
\hline
\end{tabular}

\section{4) Solubility}

The solubility studies of Rosuvastatin Calcium were determined in different solvents.

Table 3: Solubility of Rosuvastatin Calcium in different solvents

\begin{tabular}{|l|l|}
\hline Solvent & Solubility \\
\hline Water & $1.648 \pm 0.326$ \\
\hline Methanol & $2.668 \pm 0.122$ \\
\hline Phosphate buffer & $4.026 \pm 0.554$ \\
\hline \multicolumn{2}{|c|}{ Data Expressed as mean \pm S.D $(n=3)$}
\end{tabular}

Solubility of the Rosuvastatin Calcium found to be higher in phosphate buffer as compared to other solvents.

\section{5) Drug Excipients Compatibility Studies by FTIR}

Physical mixtures of both pure drug and excipients (HPMC and Ethyl Cellulose) were prepared and no major changes were observed like discoloration, liquefaction between drug and polymer and no odor of the physical mixture was found and its compatibility studies as shown in the given IR spectra in figure 3

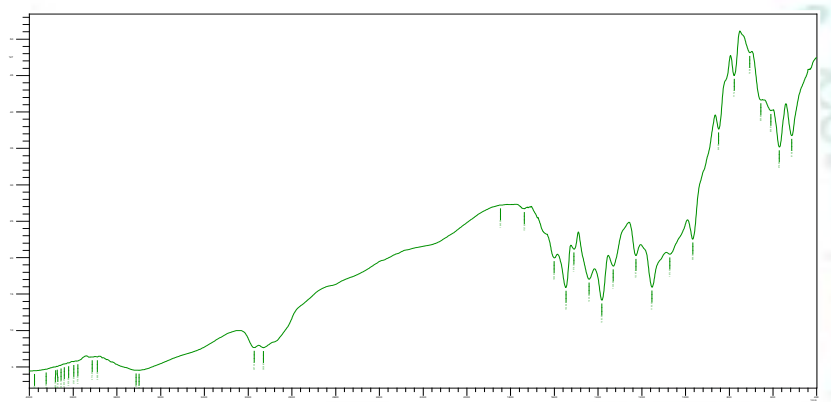

\section{Standard plot of pure drug}

The calibration curve of Rosuvastatin Calcium was found to be linear in the concentration range of 2.5-15 $\mu \mathrm{g} / \mathrm{ml}$ at $241 \mathrm{~nm}$ in Phosphate buffer ( $\mathrm{pH} \mathrm{6.8).The}$ absorbance at different concentrations is represented in figure 4 respectively.

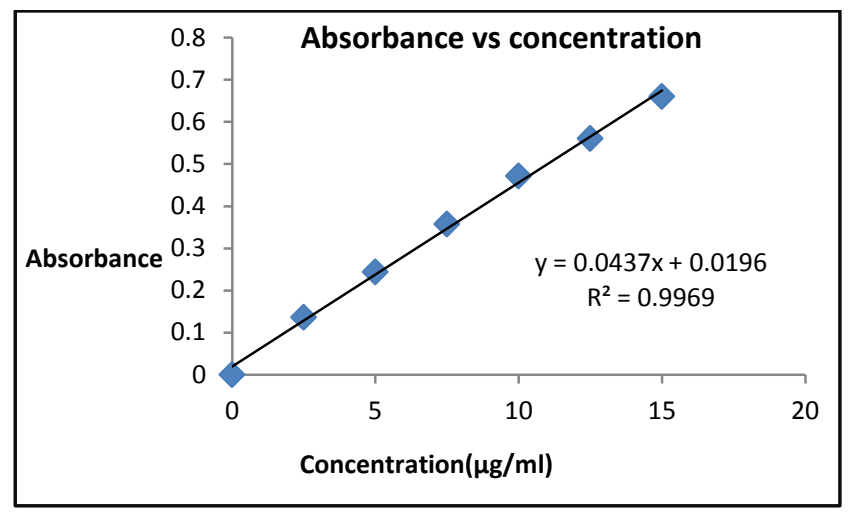

Figure 4: Standard plot of Rosuvastatin Calcium in Phosphate Buffer (pH6.8)

\section{Characterization of Solid Dispersions}

\section{1) Percent yield and drug content}

The percent yield and drug content of pure drug and different solid dispersions were determined and $\%$ yields decreases at the higher concentrations due to the difficulty in sieving due to higher polymer and surfactants concentration.

Table 4: Percent yield or drug content of solid dispersions ROS/HPMC: EC

\begin{tabular}{|c|c|c|}
\hline Formulation Code & $\begin{array}{c}\text { Percentage } \\
\text { yield }\end{array}$ & $\begin{array}{c}\text { Drug } \\
\text { content }\end{array}$ \\
\hline RS1 (1:1) & $79.46 \pm 0.056$ & $97.89 \pm 0.025$ \\
\hline RS2 (1:3) & $81.39 \pm 0.089$ & $96.55 \pm 0.069$ \\
\hline RS3 (1:5) & $83.77 \pm 0.126$ & $98.94 \pm 0.088$ \\
\hline RS4(1:7) & $85.56 \pm 0.155$ & $99.59 \pm 0.064$ \\
\hline \multicolumn{3}{|c}{ Data Expressed as mean \pm S.D $(\mathrm{n}=3)$} \\
\hline
\end{tabular}

Figure 3: IR Spectra of Mixture of Drug \& HPMC: EC

\section{2) In vitro dissolution studies}

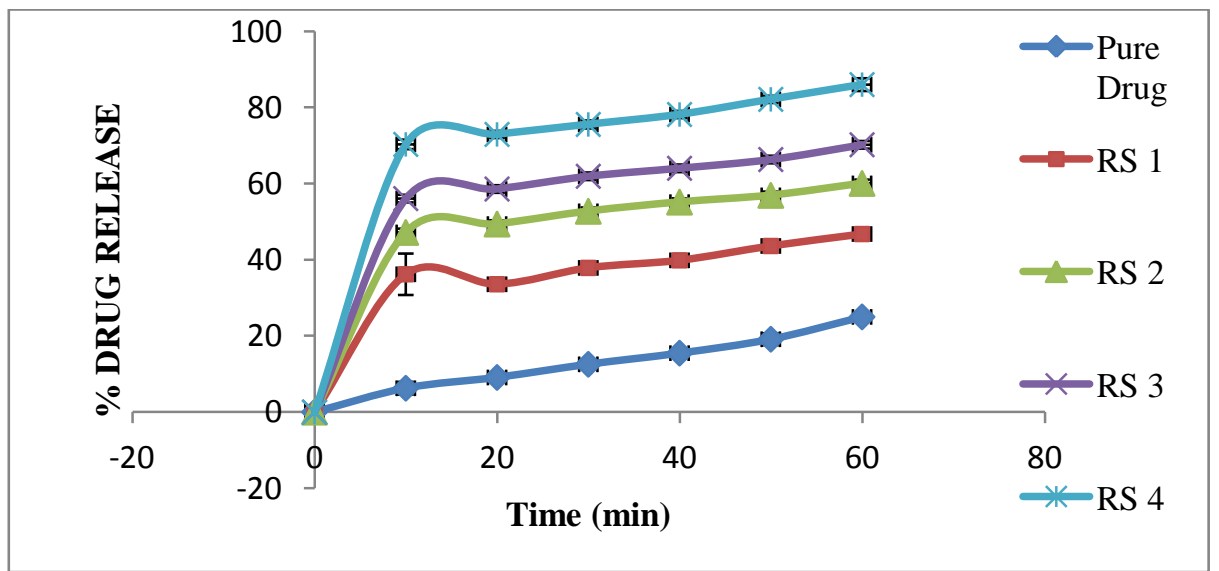

Figure 5: \% Drug release of pure drug and solid dispersion vs time 


\section{3) FTIR}

The IR Spectra of Rosuvastatin Calcium and optimized solid dispersion as shown in figure 6 and wave number is similar with the IR spectra of pure drug and change in the wave no. in the IR is due to the change in the hydrogen bonding and $\mathrm{C}-\mathrm{H}$ bending and stretching vibration of the prepared solid dispersion.

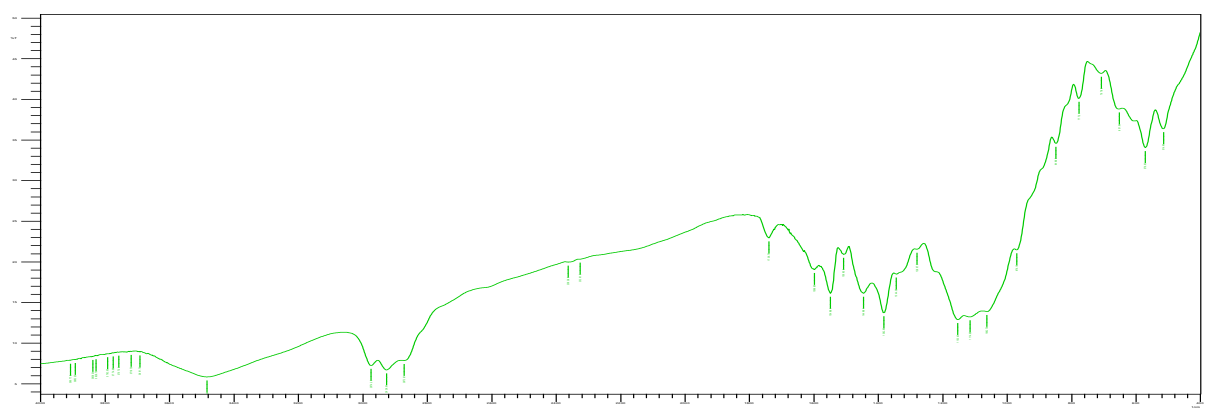

Figure 6: FTIR of Optimized batch of solid dispersion

\section{4) Differential Scanning Spectroscopy}

The DSC thermogram of Optimized solid dispersion shows no peaks in the diffractogram that indicates the change in the nature of drug from crystalline to amorphous form and reduces with the melting point as shown in Figure 7.

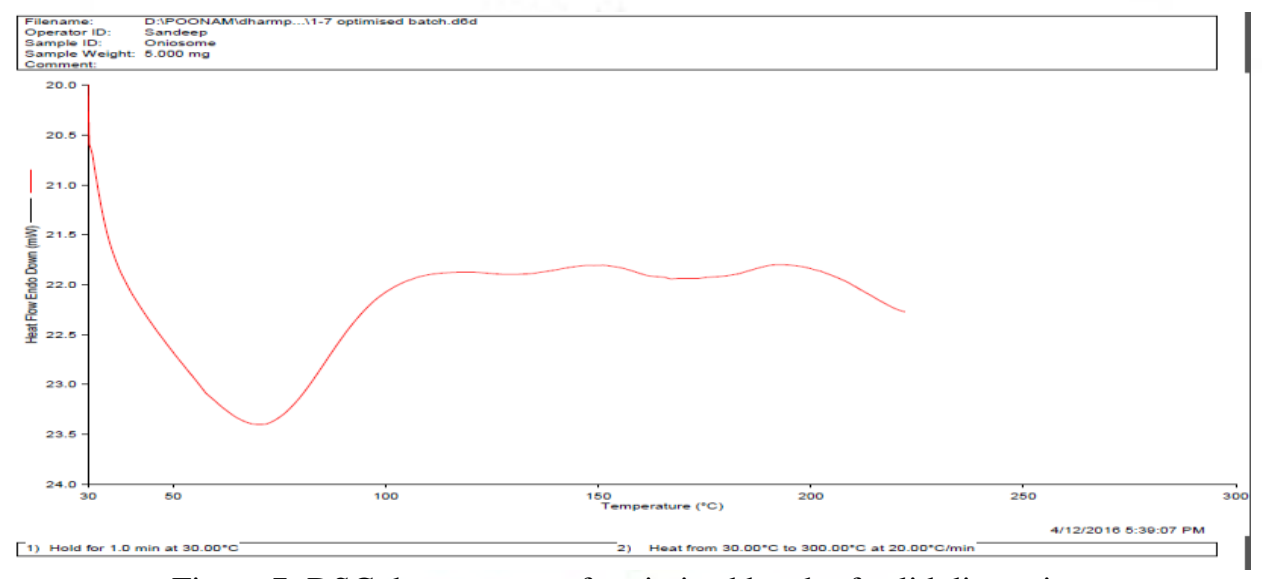

Figure 7: DSC thermogram of optimized batch of solid dispersion

\section{5) X-ray diffraction studies}

The X-ray diffraction studies of optimized solid dispersion is shown in figure 8 and reduced peak height area in the diffractogram which indicates that the change in the nature of drug from crystalline to amorphous form.

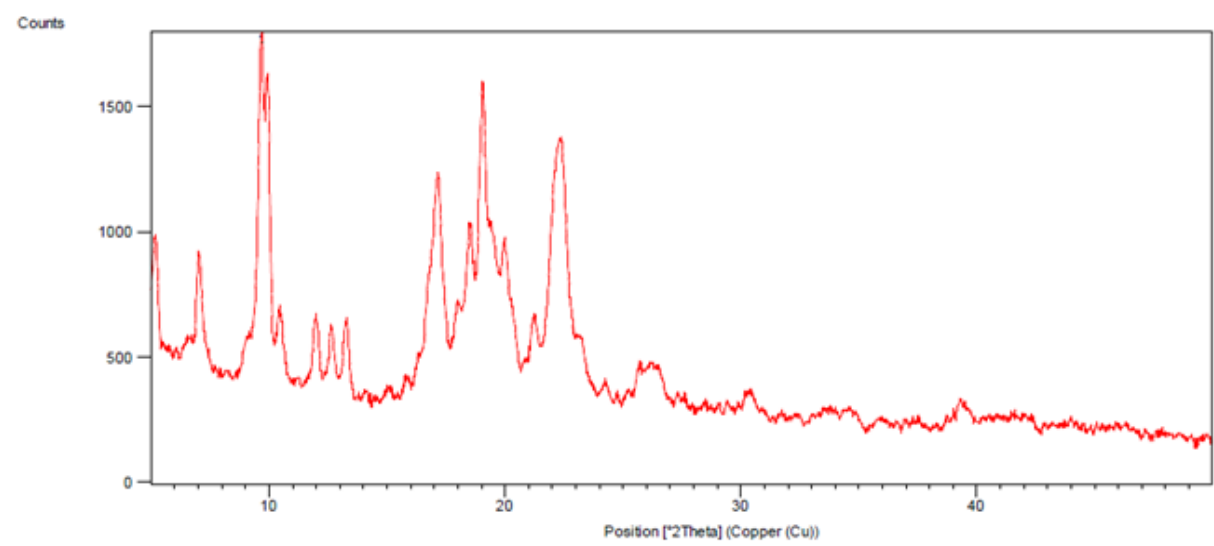

Figure 8: XRD of optimized batch of solid dispersion

\section{6) SCANNING ELECTRON MICROSCOPY}

The SEM of optimized solid dispersion shows irregular in shape and particles that indicate the change occur in the nature of the solid dispersion from crystalline to amorphous form as shown in the given Figures 9 at different magnifications. 

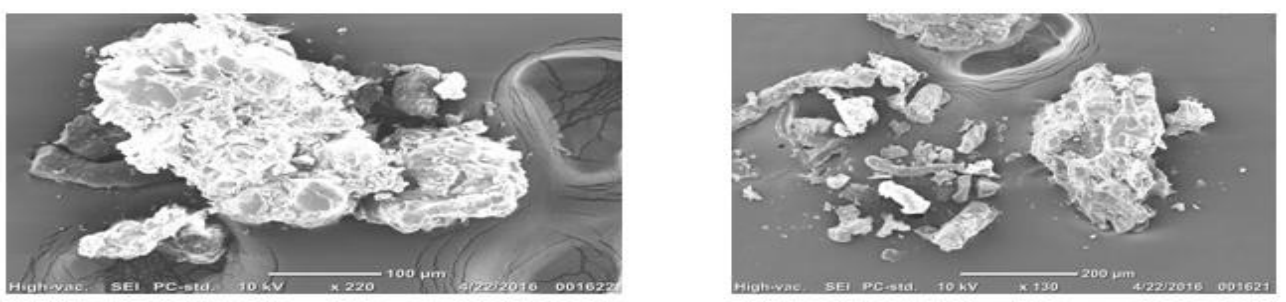

Figure 9: SEM of Optimized Batch of solid dispersion at different magnifications

\section{Characterization parameters of prepared blend dosage form}

Table 5: Blend Characteristics of Tablet dosage form

\begin{tabular}{|l|l|}
\hline Parameters & Observed Values \\
\hline Carr"s index (\%) & 11.6 \\
\hline Angle of repose $\mathbf{(}^{\mathbf{0}}$ ) & 25 \\
\hline Bulk Density (g/cc) & 0.7 \\
\hline
\end{tabular}

Data Expressed as mean \pm S.D $(n=3)$

Evaluation Parameters of Tablet dosage form

Table 6: Characterization Parameters of Optimized batch of Tablet Dosage form

\begin{tabular}{|c|l|c|c|c|c|}
\hline S.no & $\begin{array}{l}\text { Hardness } \\
(\mathbf{k g} / \mathbf{c m})\end{array}$ & $\begin{array}{l}\text { Wt. Variation } \\
(\mathbf{m g})\end{array}$ & $\begin{array}{l}\text { Disintegration Time } \\
(\mathbf{m i n})\end{array}$ & $\begin{array}{l}\text { Drug Content } \\
(\%)\end{array}$ & Percent Yield (\%) \\
\hline 1 & $4.5+0.096$ & $101.1+1.123$ & 6.22 & $99.12+0.168$ & $76.25 \pm 0.263$ \\
\hline 2 & $4.1+0.049$ & $100.3+1.068$ & 6 & $98.62+0.268$ & $78.26 \pm 0.169$ \\
\hline 3 & $4.3+0.169$ & $100.8+1.268$ & 7.46 & $99.33+0.144$ & $81.65 \pm 0.259$ \\
\hline 4 & $4.2+1.026$ & $99.1+2.569$ & 7 & $97.12+0.206$ & $75.66 \pm 0.305$ \\
\hline 5 & $4.4+0.059$ & $100.7+1.546$ & 6.30 & $95.26+0.119$ & $79.55 \pm 0.336$ \\
\hline 6 & $4.7+0.076$ & $100.6+2.056$ & 6.50 & $98.74+0.205$ & $80.99 \pm 0.289$ \\
\hline 7 & $4.6+0.088$ & $101.0+1.359$ & 7.16 & $99.65+0.116$ & $81.45 \pm 0.178$ \\
\hline 8 & $4.5+0.156$ & $100.3+2.088$ & 6 & $98.06+0.149$ & $79.84 \pm 0.166$ \\
\hline 9 & $4.2+0.169$ & $101.8+1.444$ & 7.19 & $99.84+0.256$ & $76.45 \pm 0.246$ \\
\hline 10 & $3.8+0.094$ & $102.2+2.009$ & 6 & $97.36+0.325$ & $82.11 \pm 0.209$ \\
\hline
\end{tabular}

Data Expressed as mean \pm S.D $(n=3)$

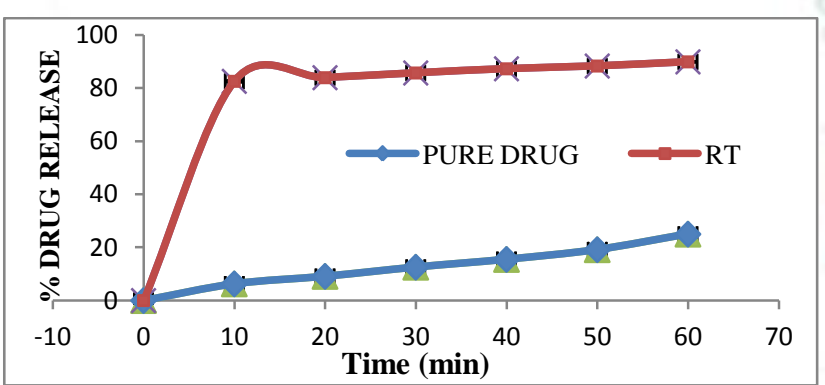

Figure 10: In vitro drug release data of Tablets Dosage form (\%drug released vs. time)

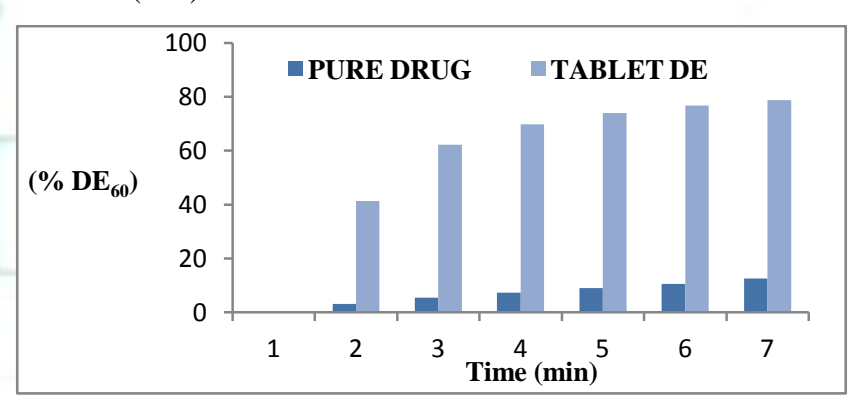

Figure 11: \% DE60 of Tablet Dosage form

\section{STABILITY TESTING OF THE TABLET DOSAGE FORM}

\section{Dissolution Data after Stability}

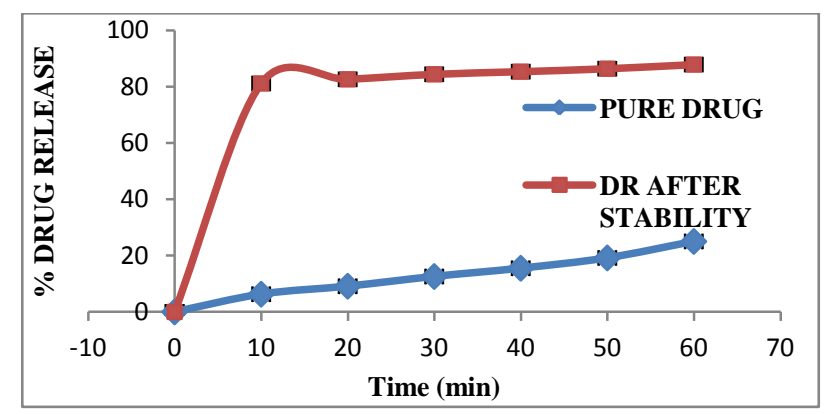

Figure 12: In vitro drug release profile of Tablets Dosage form (\%drug released vs. time) after stability studies

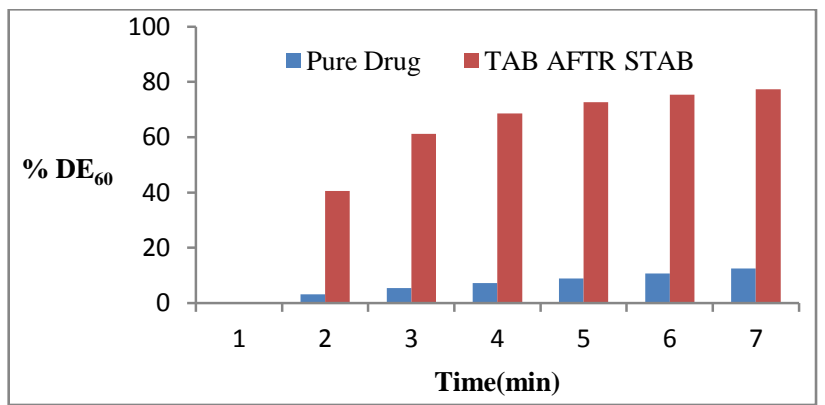

Figure 13: In vitro dissolution efficiency of Tablet Dosage form after stability studies 
The stability studies values similar with the similarity factor and the values lie between 50-100 with the similar dissolution data that indicates stability of the tablet dosage form and shelf life of the product.

\section{CONCLUSION}

One of the pharmaceutical strategies to improve the oral bioavailability, solubility and dissolution is the formulation of solid dispersions. Solid dispersions in water-soluble carriers are regarded as highly effective means of increasing the dissolution rate which in turn enhances bioavailability of various drugs. Solid dispersions increase the solubility of drug due to the conversion of the drug's crystal lattice into amorphous form, decrease in the particle size and increase in wettability caused by hydrophilic polymer.

Rosuvastatin calcium tablets were successfully prepared in this study for enhanced solubility of the drug. For this purpose model drug used should be water insoluble i.e. Rosuvastatin Calcium (lipid lowering agent). The drug was used due to its poor aqueous solubility and low dissolution rate (BCS class II), and prepared solid dispersions of Rosuvastatin Calcium that enhances the dissolution profile of poorly water-soluble drug by using different hydrophilic carriers.

Current study suggests the suitability of HPMC (hydroxypropylmethylcellulose) and EC (Ethyl cellulose) as a carrier for solid dispersions. Solid dispersions exhibited higher dissolution rates than those of physical mixtures and drug alone which is possibly due to increase in drug wettability caused by polymer used as carriers. Both HPMC and EC were used as carriers, used in different combinations by kneading method and optimized batch selected and solid dispersion of combination of both polymers are further characterized for FTIR, DSC, XRD, SEM and in vitro dissolution studies and then finally formulated into tablet dosage form.

Rosuvastatin calcium tablets prepared by wet granulation method were evaluated with different parameters such as weight variation, hardness, friability, disintegration test and in vitro dissolution tests and determine that increase in the solubility and dissolution rate of the tablet dosage form and stability studies was performed on the prepared tablet dosage form and there is no liquification, discoloration, clump formation and no change in the dissolution rate of the tablet dosage form. There is no remarkable change occur in the tablet dosage form before and after stability studies.

\section{REFERENCES}

1. Chaulang G, Patil K, Ghodke D,Khan S and Yeole P. Preparation and Characterization of Solid Dispersion Tablet of Furosemide with Crospovidone. Research J. Pharm. And Tech.2008; Vol.1(4): 386-389

2. Brahmankar D.M, Jaiswal S.B. Biopharmaceutics And Pharmacokinetics A Treatise. Vallabh Prakashan 2009;First Edition (1995):5-37

3. Sanghai B, Aggarwal G, HariKumar SL, Solid self microemulsifying drug deliviry system: a review, Journal of Drug Delivery and Therapeutics, 2013; 3(3):168-174

4. Chaulang G, Patel P, Hardikar S, Kelkar M, Bhosale A, Bhise S. Formulation and evaluation of Solid Dispersion of furosemide in Sodium Starch Glucolate. Trop J Pharma 2009; Vol.8(1): 43-51

5. Dabbagh M.A, Taghipour B.Investigation of Solid Dispersion technique in Characterstics of Ibuprofen Powder. IJPS 2007; 3(2):69-76

6. Khan AD, Singh L, Various techniques of bioavailability enhancement: a review, Journal of Drug Delivery and Therapeutics, 2016; 6(3):34-41

7. Lakade S.H, Bhalekar M.R. Different types of method for modified dosage form for Enhancement of Dissolution Rate through Solid Dispersion. IJPSR 2010; I:54-60

8. Mundhe AV, Cocrystalization: an alternative approach for solid modification, Journal of Drug Delivery and Therapeutics, 2013; 3(4):166-172

9. Rodde M.S, Divase G.T, Devkar T.B, Tikade A.R. Solubility and Bioavailability Enhancement of Poorly Aqueous Soluble Atorvastatin: In Vitro, Ex Vivo, and In Vivo Studies. Bio Med Research International; Vol 2014: Pages 10

10. Dalvi PB, Gerange AB, Ingale PR, Solid dispersion: strategy to enhance solubility, Journal of Drug Delivery and Therapeutics, 2015; 5(2):20-28

11. Alagar R.M, Rao K.N.V, Anil T, Banji D, Kumar M S, Kumar S.D. Simultaneous Estimation of Rosuvastatin Calcium and Ezetamibe in Tablet Dosage form by RP-HPLC. IJRPB 2014; Vol.2(5):1378

12. Amidon G.L, Lennernas H, Shah V. P, Crison, J. R, Theoretical basis for a biopharmaceutical drug classification: the correlation of in vitro drug product dissolution and in vivo bioavailability, Pharm Res; Vol.12(3): 413-420.

13. Serajuddin A. T. Solid dispersion of poorly water-soluble drugs: early promises, subsequent problems, and recent breakthroughs. J. Pharm. Sci; 1999 :1058-1066

14. Van den M. G. Physical stabilization of amorphous ketoconazole in solid dispersions with polyvinylpyrrolidone K25. Eur. J. Pharm.Sci; Vol. 12: 261-269.

15. Nayak A. K. Current developments in Orally disintegrating tablet technology. Journal of pharmaceutical education research 2011; 21-34.

16. Natarajan R, Komala G, Ramcy TC, Mohan S. Dissolution Enhancement Of Aceclofenac Solid Dispersion Prepared With Hydrophilic Carriers By Solvent Evaporation Method. International Journal Of Research In Pharmacy And Chemistry 2014; Vol 4(1): 83-89

17. Sathali A.A.H, Jayalakshmi J. Enhancement Of Solubility And Dissolution Rate Of Olmesartan Medoxomil By Solid Dispersion Technique. J. Curr. Chem. Pharm. Sci;Vol 3(2), 2013:123-134 